\title{
Multi Criteria Group Decision Making Approach for Smart Phone Selection Using Intuitionistic Fuzzy TOPSIS
}

\author{
Gülçin Büyüközkan ${ }^{1}$, Sezin Güleryüz ${ }^{2}$ \\ ${ }^{1}$ Industrial Engineering Department, Galatasaray University \\ Ortaköy, 34349, İstanbul, Turkey \\ E-mail: gulcin.buyukozkan@gmail.com \\ ${ }^{2}$ Industrial Engineering Department, Galatasaray University \\ Ortaköy, 34349, İstanbul, Turkey \\ E-mail: sezinguleryuz@gmail.com
}

Received 26 August 2015

Accepted 11 March 2016

\begin{abstract}
The objective of this study is to provide an effective multi criteria decision making (MCDM) approach with group decision making to evaluate different smart phone alternatives according to consumer preferences. The choice of the most appropriate phone is a very complex decision, involving several perspectives. In such complex situations intuitionistic fuzzy sets with TOPSIS (IF-TOPSIS) can be utilized to eliminate uncertainty and to better represent decision makers' preferences. The originality of the paper comes from its ability to handle high uncertainty in a smart phone selection and provide a real case study with IFS for the first time.
\end{abstract}

Keywords: Smart phone selection, Intuitionistic fuzzy sets, IF-TOPSIS, Group decision making.

\section{Introduction}

The mobile phone technology has been developed and launched in the late 1980ies, and since then it has demonstrated a continuous, rapid and widespread growth. With its young population and developing economy, Turkey has also experienced a similar trend since the introduction of this technology in 1994. As of 2014, the mobile communication industry in Turkey enjoys approximately 68 million registered mobile phones, $58 \%$ of which having access to the $3 \mathrm{G}$ technology, double of the European average ${ }^{1}$.

Presently, according to Information and Communication Technologies Authority (ICTA) there are around 72 million mobile subscribers in Turkey, corresponding to

*Corresponding author. Phone: +90 2122274480 ext:428 a ratio of $92.7 \%$ of active mobile phone lines for a consumer base. When the consumer base is limited by excluding the ages between $0-9$, then this ratio even exceeds $100 \%{ }^{2}$.

Number of mobile phones in Turkey is expected to increase and the number of $3 \mathrm{G}$ subscribers has reached to 59.4 million $^{2}$. Turkish consumers are also displaying high mobile phone usage rates with an average monthly airtime of 299 minutes, the highest in Europe ${ }^{1}$. Turkey is selected for the reason that its position as an emerging economy in Europe with a rapid smart phone market growth rate in terms of penetration rate as well as talking time per user. The spread of the technology has caused a decline of smart phone prices and a large selection of available models, giving better access for the masses. 
Following a wider consumer base, producers have started to better react to consumer expectation ${ }^{3}$ and come up with various designs and features to address different needs in the market, with regards to social and financial segmentation of the market. Moreover, access to the internet using Wi-Fi or mobile network is certainly an important feature for smart phones. With many built-in applications a mobile phone can nowadays be defined as a "smart phone".

Recently, consumers are being offered with a range of smart phones in a specific price band and the selection of a smart phone becomes an important decision problem ${ }^{5}$. Although smart phones can be used more or less for a life time of ten years, most users prefer to use their phones for a shorter time and change them with newer models. The smart phone industry proposes new features to attract users, operates competitively with rivalries and even shortens the life time of their phone models ${ }^{4}$. In addition, presenting a series of new features such as high resolution cameras, physical durability and other trends complicates the smart phone selection by consumers. Therefore, this study aims to propose a decision procedure for smart phone selection on a Turkish company. The selection procedure is ever more important for the case company, as it purchases large amounts of smart phones for its white collar personnel.

Multi criteria decision making (MCDM) refers to finding the most appropriate option where many different decision criteria are to be taken into account simultaneously ${ }^{6-7}$. In these processes, Group Decision Making (GDM) involves multiple decision makers (DMs) who have different goals or ways of thinking and can assess the decision process distinctively different from others. Nevertheless, for each of the assigned DMs there is a common interest to interact with each other in order to reach collective decision ${ }^{8-11}$. Especially when uncertainty exists, achieving consensus for a decision in a group with different opinions becomes more important ${ }^{11}$. Generally, GDM problems are solved by utilizing classic approaches, such as the majority rule, minority rule or total agreement. ${ }^{10}$ However, these techniques do not guarantee a solution that is accepted by all DMs. Therefore, Consensus Reaching Processes (CRPs) are becoming more and more necessary. ${ }^{10-11}$

Briefly, this study aims to solve this MCDM problem by using intuitionistic fuzzy sets (IFS) with
GDM approach. In this pursuit, the proposed methodology makes use of intuitionistic fuzzy technique for order performance by similarity to ideal solution, shortly called IF-TOPSIS, which has been developed by Boran $^{12}$. The underlying logic of TOPSIS ${ }^{13}$, a popular MCDM technique, is its consideration of the positive and negative ideal solutions for dealing with decision problems $^{14,15}$. In MCDM, various criteria need to be evaluated in order to reach a single alternative. However, evaluations of DMs can be rather difficult to collect and process, as the feedbacks DMs express are usually not precise. For this reason, $\mathrm{IFS}^{16}$ are utilized to eliminate uncertainty and to better represent DMs' preferences ${ }^{10}$. In recent literature, some studies have clearly indicated that IFS present a powerful method to cope with uncertainty in decision problems ${ }^{17-19}$. In contrast to the fuzzy set theory, in IFS the data information assigns a membership degree, a nonmembership degree and a hesitancy degree to each component. As stated in Xu \& Liao's research ${ }^{19}$, triangular fuzzy numbers, trapezoidal fuzzy numbers and interval-valued fuzzy numbers can only be used to depict the fuzziness of agreement but cannot reflect the disagreement of the DMs. However in real life, human beings frequently disagree, which is a common way for expressing their ideas. Hence in GDM problems IFS cope with these situations and aggregate experts' opinions for a collective decision ${ }^{19-21}$. Additionally, a TOPSIS model under intuitionistic environment is utilized to establish a flexible and robust way for DMs to better understand a decision problem in case of uncertainty and vagueness in DMs' perceptions ${ }^{20-21}$. Several publications have reported advantages of effective consideration of vague information ${ }^{19-23}$.

The main contribution of the paper is the definition and development of smart phone selection problem with IF-TOPSIS for the first time. To authors' best knowledge, no study so far has utilized this technique for the smart phone selection problem. Besides, this article also contributes to literature by presenting a case study to help corporate customers to better take decisions by evaluating and accordingly selecting the most appropriate smart phone.

This study is structured such that the $2^{\text {nd }}$ section presents a comprehensive literature review about the smart phone selection and techniques that is employed, and the $3^{\text {rd }}$ section provides a detailed description of the 
methods used. The $4^{\text {th }}$ section gives a case study of smart phone selection by using application steps of the framework. Comparison and sensitivity analysis of the results are presented in $5^{\text {th }}$ section. Finally, concluding remarks and guidance for future studies are presented in $6^{\text {th }}$ section.

\section{Literature Survey}

\subsection{Smart phone selection/evaluation}

Over years, technology and style of mobile phones such as technical features, color, design, size etc. have changed significantly. At the beginning, mobile phones focused were largely limited with voice calling functions. Nowadays, cellular phones offer many more services such as camera, messaging (e.g. SMS, MMS, email), internet access, other connection options (e.g. infrared, Bluetooth), music, business and gaming applications. Cellular phones offering such functions in addition to voice calling are generally referred to as "smart phones" 24 .

In the current telecommunications market, mobile communication is becoming popular, thus gradually increasing consumers' desire to use smart phones. Many of the products on the shelves also provide hints about the social and financial status of users, their preferences and attitudes. This turns the selection of a smart phone by a consumer into an important decision problem in which the most appropriate handset is selected even though the user is interested in smart phones in a fixed range of price. As user expectations can vary for each consumer, the selection of a smart phone can be seen as a complex MCDM problem. This study proposes a solid mechanism to support users in deciding on the most suitable mobile phone in the marketplace 5 .

Smart phones are becoming an integral component of daily and business life, so that interest in this technology and in available product alternatives in the market is rising. The Worldwide Quarterly Mobile Phone Tracker published by International Data Corporation suggests that manufacturers have shipped more than 330 million units globally in the $1^{\text {st }}$ quarter of 2015. Accordingly, the Android operating system dominated the market with more than $3 / 4$ share in the same period. Samsung, an electronics manufacturer, leads this large market by offering a wide range of smart phones, offering cutting edge as well as low-cost smart phones. In this picture, Turkey has been one of the forerunners in the adoption of mobile communications.

Presently, more than ten global smart phone vendors are actively operating in Turkey, each one having a relatively large product line $e^{25}$. As of 2015, Apple, Nokia, Samsung, LG and HTC are the top five in the Turkish smart phone market. Overall, smart phone penetration continues to rise and the number of mobile broadband subscribers (computer and mobile handset) is around 33.9 million, indicating the intensity of mobile telecommunication in Turkey.

As smart phones become powerful mobile tools, Economides and Grousopoulou ${ }^{26}$ presented students' considerations about the importance and costs of the features and services of their smart phones. In their study, the opinions of male and female students are investigated with a survey to gain insight about the importance and costs of these gadgets. Another research from Bayraktar, Tatoğlu, Turkyilmaz, Delen and Zaim ${ }^{25}$ focused on customer satisfaction and loyalty (CS\&L) for existing mobile phone brands in the Turkish market. $\mathrm{Hu}, \mathrm{Lu}$ and $\mathrm{Tzeng}^{27}$ concentrated on smart phone improvement for promoting product value to satisfy customer needs. Rahul and $\mathrm{Majhi}^{28}$ investigated consumer satisfaction and loyalty in the Indian mobile phone market. Mobile phone use behavior and differences in connection with male and female consumers is evaluated in Haverila's study ${ }^{24}$, which investigated the relationship between feature preferences and customer satisfaction and repurchase intent among young male users. An interesting research topic is the mobile phone feature preferences. Ișıklar and Büyüközkan ${ }^{5}$, Haverila ${ }^{29}$ and Haverila ${ }^{30}$ published articles on this topic. For instance, Haverila ${ }^{30}$ discussed the progressive evolution of specific smart phone feature preferences in Finland among different high school and college students.

\subsection{Smart phone evaluation criteria}

Selecting criteria is one of the most important dimensions while constructing a decision model. Therefore, criteria are important components that enable alternatives to be compared from a specific point of view. Generally, users get satisfied with a particular product when its properties match with their preferences and expectations. In order to develop an effective 
decision model, most important product selection criteria by consumers need to be identified.

In order to prepare this study and develop the proposed selection model, a series of recent publications dealing with the smart phone selection problem are reviewed. Moreover, the opinions of smart phone market experts are taken into account to identify selection criteria. Based on Işıklar and Büyüközkan's ${ }^{5}$ Haverila's ${ }^{24}$, Mokhlis and Yaakop's ${ }^{31}, \mathrm{Hu}, \mathrm{Lu}$ and Tzeng's ${ }^{27}$, Hsiao and Chen's ${ }^{4}$ studies evaluation model criteria are determined and given in Table 1. Existing literature provides various models on smart phone selection research. For instance, Işıklar and Büyüközkan ${ }^{5}$ and Chen $^{32}$ concentrated on product and user-related criteria. Işıklar and Büyüközkan ${ }^{5}$ introduced product-related criteria which consist of basic requirements, physical specifications and technical features. The user-related criteria was divided into functionality, brand choice and customer excitement. Another research by $\mathrm{Chen}, \mathrm{Hu}, \mathrm{Kuo}$ and $\mathrm{Liang}^{33}$ identified the brand, price, hardware feature/functionality, basic built-in functions and extended built-in functions as being the most essential 5 selection criteria for purchasing a smart phone. Mokhlis and Yaakop $^{31}$ summarized the selection criteria as innovative features, image, price, personal recommendation, durability and portable aspects, media influence, and post-sales service. More recently, $\mathrm{Hu}, \mathrm{Lu}$ and Tzeng $^{27}$ defined three dimensions which are customer equity, product function and mobile convenience as influencing factors for consumer willingness to purchase a smart phone. Hsiao and Chen ${ }^{4}$ came up with three demand dimensions and emphasized their differences. Accordingly, the smart phone handset, subscription to the $2 \mathrm{G} / 3 \mathrm{G}$ network and mobile services are the basic dimensions of consumer demand.

Table 1. Summary of criteria for mobile/smart phone selection

\begin{tabular}{|c|c|c|}
\hline Criteria & Descriptions & Studies in literature \\
\hline Durability & The ability to endure & $\begin{array}{l}\text { Işıklar and Büyüközkan }{ }^{5}, \text { Mokhlis and Yaakop }{ }^{31} \text {, Hsiao } \\
\text { and Chen }{ }^{4} \text {. }\end{array}$ \\
\hline Battery life & The duration of a rechargeable battery of a product & $\begin{array}{l}\text { Işılklar and Büyüközkan }{ }^{5}, \text { Economides and } \\
\text { Grousopoulou }{ }^{26}, \text { Chen, Hu, Kuo and Liang }{ }^{33}, \text { Hsiao and } \\
\text { Chen }{ }^{4} \text {. }\end{array}$ \\
\hline Changeable parts & The components that can be changed easily & Mokhlis and Yaakop ${ }^{31}$, Hsiao and Chen ${ }^{4}$ \\
\hline Dimensions & The physical characteristics of a product & $\begin{array}{l}\text { Iş1klar and Büyüközkan }{ }^{5} \text {, Chen, Hu, Kuo and Liang }{ }^{33} \text {, } \\
\text { Haverila }^{24} \text {, Hsiao and } \text { Chen }^{4} \text {,Ling, Hwang and Salvendy }\end{array}$ \\
\hline Memory capacity & $\begin{array}{l}\text { The storage capacity of data during the use of the smart } \\
\text { phone }\end{array}$ & $\begin{array}{l}\text { Chen, Hu, Kuo and Liang }{ }^{33}, \text { Haverila }^{24}, \mathrm{Hu}, \mathrm{Lu} \text { and } \\
\text { Tzeng }^{27} \text {, Hsiao and } \mathrm{Chen}^{4} \text {. }\end{array}$ \\
\hline Processor speed & The speed of programmable integrated circuit & $\mathrm{Hu}, \mathrm{Lu}$ and Tzeng ${ }^{27}, \mathrm{Hsiao}$ and $\mathrm{Chen}^{4}$. \\
\hline $\begin{array}{l}\text { Internet connection } \\
\text { speed }(4 \mathrm{G} / 5 \mathrm{G})\end{array}$ & Quality and performance of the internet connection & Hsiao and Chen ${ }^{4}$. \\
\hline Camera specifications & $\begin{array}{l}\text { The physical characteristics of camera such as } \\
\text { resolution image quality etc. }\end{array}$ & Chen, Hu, Kuo and Liang ${ }^{33}$, Hsiao and Chen ${ }^{4}$. \\
\hline $\begin{array}{l}\text { Operation system } \\
\text { easiness }\end{array}$ & $\begin{array}{l}\text { User interface and interaction functions of a smart } \\
\text { phone should be simple, plain and intuitive }\end{array}$ & Işıklar and Büyüközkan ${ }^{5}$, Haverila $^{24}$, Hsiao and $\mathrm{Chen}^{4}$. \\
\hline Variety of applications & Provides application services to consumers & Haverila $^{24}$,Hsiao and Chen ${ }^{4}$. \\
\hline Brand choice & The relation to how the customer insists on the brand & $\begin{array}{l}\text { Ișiklar and Büyüközkan }{ }^{5} \text {, Chen, } \mathrm{Hu}, \text { Kuo and Liang } \\
\text { Haverila }^{24}, \mathrm{Hu}, \mathrm{Lu} \text { and Tzeng }\end{array}$ \\
\hline Prestige & The reputation of a product & $\begin{array}{l}\text { Mokhlis and Yaakop }{ }^{31}, \text { Haverila }^{24} \text {, Bayraktar, Tatoğlu, } \\
\text { Turkyilmaz, Delen and Zaim }{ }^{24} \text {. }\end{array}$ \\
\hline $\begin{array}{l}\text { Fashionable style/ } \\
\text { Aesthetics }\end{array}$ & Conforming to the current styles or trends of a product & $\begin{array}{l}\text { Işıklar and Büyüközkan }{ }^{5} \text {,Chen, Hu, Kuo and Liang }{ }^{33} \text {, } \\
\text { Haverila }^{24}, \text { Mokhlis and Yaakop }{ }^{31} \text {, Hsiao and Chen }{ }^{4} \text {. }\end{array}$ \\
\hline $\begin{array}{l}\text { Personal information } \\
\text { and media security }\end{array}$ & The resistance degree or protection from harm & Iş1klar and Büyüközkan ${ }^{5}$, Haverila $^{24}$. \\
\hline Price & $\begin{array}{l}\text { It refers to reasonable cost/price and often serves as a } \\
\text { quality indicator }\end{array}$ & $\begin{array}{l}\text { Iş1klar and Büyüközkan }{ }^{5} \text { Chen, Hu, Kuo and Liang }{ }^{33} \text {, } \\
\text { Haverila }^{24}, \text { Mokhlis and Yaakop }\end{array}$ \\
\hline $\begin{array}{l}\text { Warranty / Service } \\
\text { Availability }\end{array}$ & $\begin{array}{l}\text { It represents guarantee which provide assurance to } \\
\text { consumers dealing with problems. }\end{array}$ & $\begin{array}{l}\text { Ișiklar and Büyüközkan }{ }^{5} \text {, Haverila }{ }^{24} \text {, Mokhlis and } \\
\text { Yaakop }^{31} \text {. }\end{array}$ \\
\hline
\end{tabular}


The structure of the proposed model make use of the following criteria: Consumers highly regard physical conditions in selecting their phones, including Durability, Battery life, Changeable parts, Dimensions. Physical conditions refer to the design standards of a product and constitute an essential component. These conditions can differ from product to product. Haverila $^{24}$ underlined the importance of various feature preferences. This preference consideration becomes particularly important as manufacturers have many feature alternatives to add to a phone model among a large set of potential features. A large number of technical features, however, do not necessarily affect consumers towards a positive purchase decision. Embedding too many features might even have a negative impact on consumers if these features can be perceived to be unnecessary or complicated. Therefore, basic conditions appear to be grouped together.

Technical conditions refer to the technological assistance of products and include Memory capacity, Processor speed, Internet connection speed $(4 \mathrm{G} / 5 \mathrm{G})$ and Camera specifications. Beside hardware, consumers also value the software on a mobile phone, i.e. Functionality conditions. Operation system easiness and Variety of applications are among the most interesting features ${ }^{35}$.

Brand/Market conditions involves the subjective and invisible evaluation of the brand based on the brand awareness, the brand ethics and the brand attitude of the customer. Brand/Market conditions include Brand choice, Prestige, Fashionable style/Aesthetics, Personal information and media security, Price and Warranty/Service Availability. In mobile sector, consumers are facing higher security and privacy risks because of the data transaction in a wireless environment.

\subsection{IF-TOPSIS with GDM environment}

MCDM is one of the popular methods to deal with complicated problems that exhibit high uncertainty, clashing objectives, various interests and multiple perspectives $^{32-34}$. Besides, MCDM methods are effective in decision making, weighting and selecting the most appropriate alternatives ${ }^{17-18}$. A number of researchers have used different MCDM techniques in the fields of information, mobile communications, music business and gaming applications ${ }^{35,36}$. For instance; Işıklar and
Büyüközkan ${ }^{5}$ developed a MCDM technique where they evaluated different mobile phone options with respect to users' preferences by applying AHP and TOPSIS. Chen, $\mathrm{Hu}$, Kuo and Liang ${ }^{33}$ proposed recommendation systems for online mobile phone stores by using an AHP-based mechanism. $\mathrm{Hu}, \mathrm{Lu}$ and Tzeng $^{27}$ proposed a hybrid MCDM model for promoting a smart phone's product value by using DEMATEL, ANP and VIKOR. Apart from these MCDM techniques, this study utilized Intuitionistic Fuzzy Sets (IFS) introduced by Atanassov $^{16,37}$. IFS can be seen as the extension of fuzzy sets which was originally proposed by $\mathrm{Zadeh}^{38}$. IFS can be characterized by the components of a membership function, a non-membership function and a margin for hesitation. It is flexible for dealing with uncertainty, whereas fuzzy sets are characterized by only their membership function ${ }^{16}$.When the individual evaluations of DMs in a GDM under uncertainty are concerned, it must be taken into account that not all DMs have the same level of knowledge, background and experience. They can differ in terms of skills, personality or area of research $^{39,40}$. Therefore, uncertainty is natural for DMs when providing their preferences, exhibiting characteristics of affirmation, negation, and hesitation to some extent ${ }^{41,42}$. IFS can in such cases be a helpful tool with its flexibility and robustness ${ }^{17,18}$. IFS can also take the degree of hesitation into account and can deal with any error or lack of knowledge in defining the membership function. Beside these advantages, IFS can also cope with uncertain and vague objects. As such, it provides researchers and DMs with a powerful tool for expressing data under different fuzzy environments ${ }^{17,19}$.

Integration with GDM can be exemplified in $\mathrm{Xu}$ and Liao's research ${ }^{19}$. It is stated that triangular fuzzy numbers, trapezoidal fuzzy numbers and interval-valued fuzzy numbers can only be used to depict the fuzziness of agreement but cannot reflect the disagreement among DMs. However, in real life recognition of human beings' disagreement is a common expression for effectively describing and communicating opinions. Hence IFS copes with such situations and aggregates experts' opinions for a collective decision in GDM problems $^{43}$.

A key approach in GDM problems is to include many alternatives and DMs from different or same disciplines to find the most suitable solution among a set of available alternatives and attempt to reach a 
collective decision ${ }^{44,45}$. Aggregation of expert opinions plays a central role in reaching a collective decision with an evaluation process ${ }^{46,47}$. For this purpose, the technique called intuitionistic fuzzy weighted averaging (IFWA) operator is proposed by $\mathrm{Xu}^{40}$. IFWA can be used for merging the opinions of each individual DM together, where the aggregated result is used for assigning a value to the importance of selection criteria and available alternatives ${ }^{12,43}$. Besides, $\mathrm{Xu}$ and $\mathrm{Yager}^{48}$ introduced additional intuitionistic fuzzy geometric aggregation operators, such as intuitionistic fuzzy weighted geometric averaging operator (IFWGA), intuitionistic fuzzy ordered weighted geometric averaging operator (IFOWGA) and intuitionistic fuzzy hybrid geometric averaging operator (IFHGA). $\mathrm{Xu}^{40}$ presented some other intuitionistic fuzzy aggregation operators, such as intuitionistic fuzzy ordered weighted averaging (IFOWA) operator and the intuitionistic fuzzy hybrid averaging (IFHA) operator. $\mathrm{He}$, Chen, Zhou, Liu and $\mathrm{TaO}^{49}$ developed another operator, intuitionistic fuzzy geometric interaction averaging (IFGIA) operator.

Following these valuable developments in literature and other important contributions, researchers recently started to investigate IFS in MCDM. As one of best known MCDM methods, TOPSIS technique was initially proposed by Chen and Hwang ${ }^{50}$. The developed
TOPSIS method proposed by Hwang and Yoon $^{13}$ incorporates a simple computation process, systematic procedure, and a solid logic that considers the rationale of people's choices. In this paper, TOPSIS is utilized as a ranking technique based on its rational logic and understandability ${ }^{14}$. Although TOPSIS is very popular to solve MCDM problems, this approach also has some weaknesses. A better approach may be to use IFS rather than fuzzy sets, where criteria ratings and weights are found with intuitionistic numbers. Recently, many researchers extended IF-TOPSIS for MCDM. These methodologies have been applied satisfactorily to different research areas for evaluation purposes and these are summarized in Table 2.

As seen in Table 2, IF-TOPSIS is integrated with different techniques in various fields of application. On the other hand, IF-TOPSIS is utilized with interval valued approach which is different from Boran's ${ }^{12-14}$ proposed approach. To authors' best knowledge; there exists no publication in which IF-TOPSIS is used for the smart phone selection problem. Therefore, this paper contributes to the literature by addressing this research gap and demonstrating the applicability of the proposed method with a case study.

Table 2. Several studies make use of IF-TOPSIS

\begin{tabular}{|c|c|c|c|}
\hline Year & Authors & Intuitionistic type & Application area \\
\hline 2009 & Boran, Genc, Kurt and Akay ${ }^{14}$ & TOPSIS, GDM & Illustrative example (Supplier selection) \\
\hline 2009 & Boran $^{12}$ & TOPSIS & Case study (Personnel selection) \\
\hline 2010 & $\mathrm{Ye}^{51}$ & Interval-valued IFS, TOPSIS, GDM & Illustrative example (Partner selection) \\
\hline 2011 & Boran $^{52}$ & TOPSIS & Illustrative example (Facility location selection) \\
\hline 2011 & $\operatorname{Tan}^{53}$ & $\begin{array}{l}\text { Interval-valued intuitionistic fuzzy sets } \\
\text { Choquet integral, TOPSIS }\end{array}$ & Illustrative example (Investment selection) \\
\hline 2011 & $\mathrm{Su}$, Chen, Xia and Wang ${ }^{54}$ & TOPSIS, consensus & Illustrative example (3PL logistic provider selection) \\
\hline 2012 & Boran, Boran and Menlik ${ }^{43}$ & TOPSIS & Case study (Renewable energy resource selection) \\
\hline 2013 & Intepe, Bozdağ and Koç & Interval-valued IFS, TOPSIS, GDM & Case study (3D TV technology selection) \\
\hline 2013 & $\begin{array}{l}\text { Vahdani, Mousavi, } \\
\text { Moghaddam and Hashemi }{ }^{56}\end{array}$ & ELECTRE, TOPSIS,GDM & $\begin{array}{l}\text { Illustrative example (Flexible manufacturing systems } \\
\text { selection) }\end{array}$ \\
\hline 2014 & $\begin{array}{l}\text { Kucukvar, Gumus, Egilmez, } \\
\text { and Tatari }^{57}\end{array}$ & TOPSIS & Illustrative example (Asphalt pavement selection) \\
\hline 2014 & Joshi and $\mathrm{Kumar}^{23}$ & TOPSIS, entropy & Case study (Portfolio selection) \\
\hline 2014 & $\begin{array}{l}\text { Maldonado-Macías, Alvarado, } \\
\text { García, and Balderrama }^{22}\end{array}$ & TOPSIS, AHP & Illustrative example (Milling machine selection) \\
\hline 2014 & $Y_{u e^{20}}$ & TOPSIS & $\begin{array}{l}\text { Illustrative example (Chinese universities' satisfaction } \\
\text { evaluation) }\end{array}$ \\
\hline 2015 & Chen $^{58}$ & Interval-valued IFS, TOPSIS, GDM & Illustrative example (Medical treatment method selection) \\
\hline 2015 & Zhang and $\mathrm{Xu}^{59}$ & Interval-valued IFS, TOPSIS & Illustrative example (Supplier selection) \\
\hline
\end{tabular}




\section{The Applied Methodology}

This section briefly summarizes the methodology to be utilized in the paper for solving mobile phone selection problem. First, basic knowledge about IFS is presented and then the computational steps of IF-TOPSIS with GDM are explained.

\subsection{Preliminaries}

The methodology explained in this section first presents the basic definitions and notations of IFS, most of which are taken from Atanassov's study. ${ }^{37}$ In a finite set of X, IFS $S$ can be stated as:

$$
S=\left\{\left\langle x, \mu_{S}(x), v_{S}(x)\right\rangle x \in X\right\}
$$

Here, $\mu_{S}(x), v_{(S)}(x): \mathrm{X} \rightarrow[0,1]$ is the membership function and the non membership function respectively, so that,

$$
0 \leq \mu_{S}(x)+v_{S}(x) \leq 1
$$

In IFS, there is another parameter $\pi(x)$, called the "hesitation degree" that checks if $\mathrm{x}$ belongs to $\mathrm{S}$,

$$
\pi_{S}=1-\mu_{S}(x)-v_{S}(x)
$$

Here, for every $\mathrm{x} \in \mathrm{X}$ :

$$
0 \leq \pi_{S}(x) \leq 1
$$

As $\pi_{S}(x)$ becomes smaller, the certainty of the knowledge about $\mathrm{x}$ becomes higher. As $\pi_{S}(x)$ gets higher, then the knowledge about $\mathrm{x}$ becomes less certain. In this case, when $\mu_{S}(x)=1-v_{S}(x)$ for each and every element of the universe, the concept of ordinary fuzzy set is recovered. Defining $\mathrm{M}$ and $\mathrm{N}$ as two IFSs that belong to the set of $X$, then the multiplication operator can be defined as the following. ${ }^{39}$

$$
\begin{gathered}
M \otimes N=\left\{\mu_{M}(x) \cdot \mu_{N}(x), v_{M}(x) \cdot v_{N}(x)-\right. \\
\left.v_{M}(x) \cdot v_{N}(x) \mathrm{I} x \in X\right\}
\end{gathered}
$$

\subsection{IF-TOPSIS}

The general view of GDM based approach of IFTOPSIS is given in "Fig. 1". The methodology of IF-
TOPSIS is adapted from Boran's studies ${ }^{12-14}$. The summary view of this framework starts with identifying evaluation criteria and alternatives using experts' opinions and a detailed literature review is required to search and collect information. Next, a committee of experts is necessary to provide group decision. According to the group qualifications, different weights are determined for each DM. Then a comparison scale to weight criteria set and rate alternatives are selected. In the next phase an aggregated intuitionistic fuzzy decision matrix is constructed based on DMs assessments. Then criteria weights based on DMs assessments is obtained. The framework concludes with focusing on the selection process. Here, TOPSIS is adapted to the system for ranking available alternatives of smart phones in a decreasing order using their relative closeness coefficient. The steps of the IFTOPSIS are explained briefly as follows:

Define $A=\left\{A_{1}, A_{2}, \ldots, A_{m}\right\}$ as a set of alternatives and $X=\left\{X_{1}, X, \ldots, X_{n}\right\}$ as a set of criteria.

Step 1: Identify the evaluation criteria and alternatives for the smart phone selection problem. The objective is to find out the most appropriate smart phone alternatives among the others.

Step 2: Find the weights of DMs' evaluations. Here, the decision committee consists of three DMs. The importance degrees of each of the DM evaluations are processed as linguistic terms expressed in IFS. Assume that $D_{k}=\left[\mu_{k}, v_{k}, \pi_{k}\right]$ is an intuitionistic fuzzy number with the rating of $\mathrm{k}^{\text {th }} \mathrm{DM}$. Accordingly, the weight of the $\mathrm{k}^{\text {th }} \mathrm{DM}$ can be obtained as:

$$
\begin{gathered}
\lambda_{k}=\frac{\left(\mu_{k}+\pi_{k}\left(\frac{\mu_{k}}{\mu_{k}+v_{k}}\right)\right)}{\sum_{k=1}^{l}\left(\mu_{k}+\pi_{k}\left(\frac{\mu_{k}}{\mu_{k}+v_{k}}\right)\right)} \quad \text { and } \\
\sum_{k=1}^{l} \lambda_{k}=1
\end{gathered}
$$

Step 3: Select a comparison scale to weight criteria set and rate alternatives. Linguistic label sets with their respective IFS are given in Table 3 and 4 as follows: 


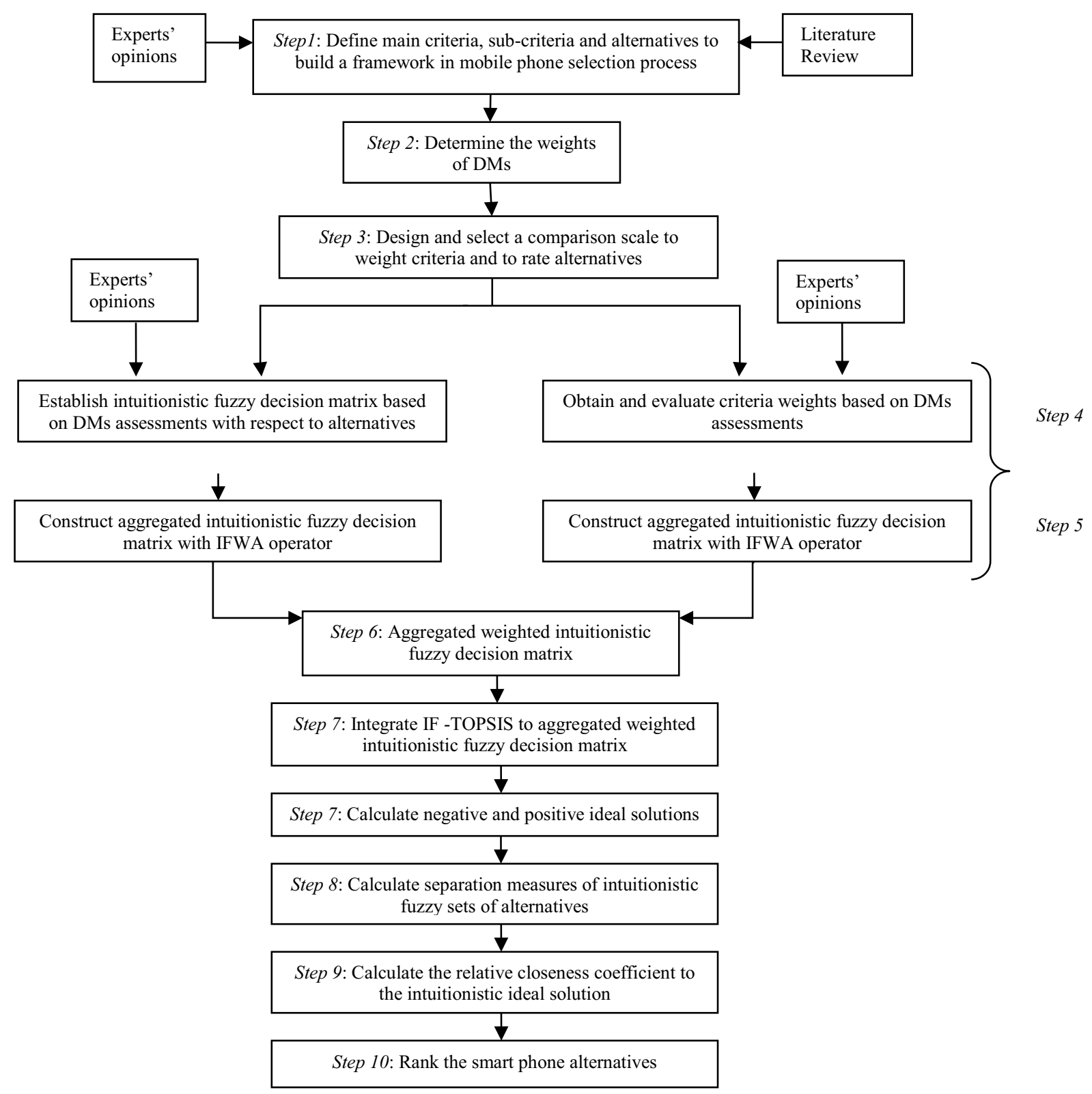

Fig. 1. Schematic diagram of IF-TOPSIS

Table 3. Linguistic terms for rating criteria

\begin{tabular}{ll}
\hline Linguistic term & $I F S$ \\
\hline Very Important (VI) & {$[0.9 ; 0]$} \\
Important (I) & {$[0.8 ; 0.1]$} \\
Moderately Important (MI) & {$[0.7 ; 0.2]$} \\
Medium (M) & {$[0.5 ; 0.5]$} \\
Unimportant (U) & {$[0.3 ; 0.5]$} \\
Very Unimportant (VU) & {$[0.2 ; 0.7]$} \\
\hline
\end{tabular}

Step 4: Form an aggregated intuitionistic fuzzy decision matrix that is based on DMs' assessments. Assume that $R^{(k)}=\left(r_{i j}^{k}\right)_{m x n}$ is an intuitionistic fuzzy decision matrix for each DM. Let $\lambda=\left(\lambda_{1}, \lambda_{2}, . ., \lambda_{l}\right)$ be the weight of each $\mathrm{DM}$ and $\sum_{k=1}^{l} \lambda_{k}=1, \lambda_{k} \epsilon[0,1]$. Operator IFWA will then be used to aggregate DMs' evaluations in order to rate the importance values of decision criteria and available alternatives in the GDM process. 
Table 4. Linguistic terms for rating alternatives

\begin{tabular}{ll}
\hline Linguistic terms & IFS \\
\hline Extremely Good (EG) & {$[1,0,0]$} \\
Very Good (VG) & {$[0.75,0.1,0.15]$} \\
Good (G) & {$[0.6,0.25,0.15]$} \\
Moderately Good (MG) & {$[0.5,0.4,0.1]$} \\
Medium (M) & {$[0.5,0.5,0]$} \\
Moderately Bad (MB) & {$[0.4,0.5,0.1]$} \\
Bad & {$[0.25,0.6,0.15]$} \\
Very Bad (VB) & {$[0.1,0.75,0.15]$} \\
Very very Bad (VVB) & {$[0,0.9,0.1]$} \\
\hline
\end{tabular}

$R=\left(r_{i j}\right)_{m x n}$ and $r_{i j}=\left(\mu_{A_{i}}\left(x_{j}\right), v_{A_{i}}\left(x_{j}\right), \pi_{A_{i}}\left(x_{j}\right)\right)$ $\mathrm{i}=(1,2, . ., \mathrm{m} ; \mathrm{j}=1,2, . ., \mathrm{n})$

$$
\begin{aligned}
& r_{i j}=I F W A_{\lambda}\left(r_{i j}^{(1)}, r_{i j}^{(2)}, \ldots, r_{i j}^{(l)}\right) \\
& =\lambda_{1} r_{i j}^{(1)} \oplus \lambda_{2} r_{i j}^{(2)} \oplus \lambda_{3} r_{i j}^{(3)} \oplus \ldots \oplus \lambda_{l} r_{i j}^{(l)} \\
& =\left[1-\prod_{k=1}^{l}\left(1-\mu_{i j}^{(k)}\right)^{\lambda_{k}}, \prod_{k=1}^{l}\left(v_{i j}^{(k)}\right)^{\lambda_{k}}, \prod_{k=1}^{l}(1-\right. \\
& \left.\left.\mu_{i j}^{(k)}\right)^{\lambda_{k}},-\prod_{k=1}^{l}\left(v_{i j}^{(k)}\right)^{\lambda_{k}}\right]
\end{aligned}
$$

Then intuitionistic fuzzy decision matrix can be defined as:

$$
\begin{gathered}
R \\
=\left[\begin{array}{ccccc}
\mu_{A_{1}}\left(x_{1}\right), v_{A_{1}}\left(x_{1}\right), \pi_{A_{1}}\left(x_{1}\right) & \mu_{A_{1}}\left(x_{2}\right), v_{A_{1}}\left(x_{2}\right), \pi_{A_{1}}\left(x_{2}\right) & \ldots & \mu_{A_{1}}\left(x_{n}\right), v_{A_{1}}\left(x_{n}\right), \pi_{A_{1}}\left(x_{n}\right) \\
\mu_{A_{2}}\left(x_{1}\right), v_{A_{2}}\left(x_{1}\right), \pi_{A_{2}}\left(x_{1}\right) & \mu_{A_{2}}\left(x_{2}\right), v_{A_{2}}\left(x_{2}\right), \pi_{A_{2}}\left(x_{2}\right) & \ldots & \mu_{A_{2}}\left(x_{n}\right), v_{A_{2}}\left(x_{n}\right), \pi_{A_{2}}\left(x_{n}\right) \\
\vdots & \vdots & \ddots & \vdots \\
\mu_{A_{m}}\left(x_{1}\right), v_{A_{m}}\left(x_{1}\right), \pi_{A_{m}}\left(x_{1}\right) & \mu_{A_{m}}\left(x_{2}\right), v_{A_{m}}\left(x_{2}\right), \pi_{A_{m}}\left(x_{2}\right) & \ldots & \mu_{A_{m}}\left(x_{n}\right), v_{A_{m}}\left(x_{n}\right), \pi_{A_{m}}\left(x_{n}\right)
\end{array}\right] \\
R=\left[\begin{array}{ccccc}
r_{11} & r_{12} & r_{13} & \ldots & r_{1 m} \\
r_{21} & r_{22} & r_{23} & \ldots & r_{2 m} \\
r_{31} & r_{32} & r_{33} & \ldots & r_{3 m} \\
\vdots & \vdots & \vdots & \ddots & \vdots \\
r_{n 1} & r_{n 2} & r_{n 3} & \ldots & r_{n m}
\end{array}\right]
\end{gathered}
$$

Step 5: Construct and evaluate weights of criteria according to DMs' viewpoints. The importance degrees of each criteria can be shown with "W". Then, in order to evaluate importance degrees, all individual opinions have to be fused. Here, $W_{j}^{(k)}=\left[\mu_{j}^{(k)}, v_{j}^{(k)}, \pi_{j}^{(k)}\right]$ is defined as IFS that is assigned to criteria $\mathrm{X}_{\mathrm{j}}$ by the $\mathrm{k}^{\text {th }}$ DM. Their criteria weights are calculated as follows:

$$
\begin{aligned}
& W_{j}=I F W A_{\lambda}\left(W_{j}^{(1)}, W_{j}^{(2)}, \ldots, W_{j}^{(l)}\right) \\
& =\lambda_{1} W_{j}^{(1)} \oplus \lambda_{2} W_{j}^{(2)} \oplus \lambda_{3} W_{j}^{(3)} \oplus \ldots \oplus \lambda_{l} W_{j}^{(l)} \\
& =\left[1-\prod_{k=1}^{l}\left(1-\mu_{j}^{(k)}\right)^{\lambda_{k}}, \prod_{k=1}^{l}\left(v_{j}^{(k)}\right)^{\lambda_{k}}, \prod_{k=1}^{l}(1-\right. \\
& \left.\left.\mu_{j}^{(k)}\right)^{\lambda_{k}},-\prod_{k=1}^{l}\left(v_{j}^{(k)}\right)^{\lambda_{k}}\right] \\
& W=\left[W_{1}, W_{2}, W_{3}, \ldots, W_{j}\right] \\
& W_{j}=\left[\mu_{j}, v_{j}, \pi_{j}\right](j=1,2, . ., n) .
\end{aligned}
$$

Step 6: Establish the aggregated weighted intuitionistic fuzzy decision matrix based on the previously constructed criteria weights (W) and the aggregated intuitionistic fuzzy decision matrix, as shown below:

$$
\begin{aligned}
& \quad R \otimes W=\left\{\left\langlex, \mu_{A_{i}}(x) \cdot \mu_{w}(x), v_{A_{i}}(x)+\right.\right. \\
& \left.\left.v_{w}(x)-v_{A_{i}}(x) \cdot v_{w}(x)\right\rangle I x \in X\right\} \\
& \text { Next, } \\
& \pi_{A_{i}} w(x)=1-v_{A_{i}}(x)-v_{w}(x)-\mu_{A_{i}}(x) \cdot \mu_{w}(x)+ \\
& v_{A_{i}}(x) \cdot v_{w}(x)
\end{aligned}
$$

Finally, the aggregated weighted intuitionistic fuzzy decision matrix is found as:

$$
R^{\prime}=\left[\begin{array}{ccccc}
r_{11}^{\prime} & r_{12}^{\prime} & r_{13}^{\prime} & \ldots & r_{1 m}^{\prime} \\
r^{\prime}{ }_{21} & r^{\prime}{ }_{22} & r^{\prime}{ }_{23} & \ldots & r_{2 m}^{\prime} \\
r_{31}^{\prime} & r_{32}^{\prime} & r^{\prime}{ }_{33} & \ldots & r_{3 m}^{\prime} \\
\vdots & \vdots & \vdots & \ddots & \vdots \\
r_{n 1}^{\prime} & r_{n 2}^{\prime} & r_{n 3}^{\prime} & \ldots & r_{n m}^{\prime}
\end{array}\right]
$$

$r_{i j}^{\prime}=\left(\mu_{i j}^{\prime}, v_{i j}^{\prime}, \pi_{i j}^{\prime}\right)=\left(\mu_{A_{i} W}\left(x_{j}\right), v_{A_{i} W}\left(x_{j}\right), \pi_{A_{i} W}\left(x_{j}\right)\right)$ is an element of the aggregated weighted intuitionistic fuzzy decision matrix, as found above.

Step 7: Integrate IF-TOPSIS to aggregated weighted intuitionistic fuzzy decision matrix. Following that, calculate the distances from positive and negative ideal points. Assume that $\mathrm{J}_{1}$ represents the benefit criteria and $\mathrm{J}_{2}$ represents the cost criteria. Here, $\mathrm{A}^{+}$is defined as the intuitionistic fuzzy positive-ideal solution and $\mathrm{A}^{-}$is defined as the intuitionistic fuzzy negative-ideal solution, as shown below:

$$
\begin{aligned}
A^{+} & =\left(\left(\mu_{A^{+} W}\left(x_{j}\right), v_{A^{+} W}\left(x_{j}\right)\right)\right. \text { and } \\
A^{-} & =\left(\left(\mu_{A^{-} W}\left(x_{j}\right), v_{A^{-} W}\left(x_{j}\right)\right)\right. \text { where, }
\end{aligned}
$$

$\mu_{A^{+} W}\left(x_{j}\right)=$

$\left(\left(\max _{i} \mu_{A_{i} \cdot W}\left(x_{j}\right) \mid j \epsilon J_{1}\right),\left(\min _{i} \mu_{A_{i} \cdot W}\left(x_{j}\right) \mid j \epsilon J_{2}\right)\right)$

$v_{A^{+} W}\left(x_{j}\right)=$

$\left(\left(\min _{i} v_{A_{i} \cdot W}\left(x_{j}\right) \mid j \epsilon J_{1}\right),\left(\max _{i} v_{A_{i} \cdot W}\left(x_{j}\right) \mid j \epsilon J_{2}\right)\right)$

$\mu_{A^{-} W}\left(x_{j}\right)=$

$\left(\left(\min _{i} \mu_{A_{i} \cdot W}\left(x_{j}\right) \mid j \epsilon J_{1}\right),\left(\max _{i} \mu_{A_{i} \cdot W}\left(x_{j}\right) \mid j \epsilon J_{2}\right)\right)$

$v_{A-W}\left(x_{j}\right)=\left(\left(\max _{i} v_{A_{i} . W}\left(x_{j}\right) \mid j \epsilon J_{1}\right),\left(\min _{i} v_{A_{i} . W}\left(x_{j}\right) \mid j \epsilon J_{2}\right)\right)$ 
Step 8: Calculate the separation measures of the intuitionistic fuzzy sets of the available alternatives. The distance of each alternative from the positive and negative ideal points are computed as follows:

$$
\begin{aligned}
& S^{+} \\
& =\sqrt{\frac{1}{2 n} \sum_{j=1}^{n}\left[\left(\mu_{A_{i} W}\left(x_{j}\right)-\mu_{A^{+} W}\left(x_{j}\right)\right)^{2}+\left(v_{A_{i} W}\left(x_{j}\right)-v_{A^{+} W}\left(x_{j}\right)\right)^{2}+\left(\pi_{A_{i} W}\left(x_{j}\right)-\pi_{A^{+} W}\left(x_{j}\right)\right)^{2}\right]} \\
& S^{-} \\
& =\sqrt{\frac{1}{2 n} \sum_{j=1}^{n}\left[\left(\mu_{A_{i} W}\left(x_{j}\right)-\mu_{A^{-} W}\left(x_{j}\right)\right)^{2}+\left(v_{A_{i} W}\left(x_{j}\right)-v_{A^{-} W}\left(x_{j}\right)\right)^{2}+\left(\pi_{A_{i} W}\left(x_{j}\right)-\pi_{A^{+} W}\left(x_{j}\right)\right)^{2}\right]}
\end{aligned}
$$

Step 9: Find the relative closeness coefficient $\left(\mathrm{CC}_{\mathrm{i}}\right)$ for the intuitionistic ideal solution. For an alternative $A_{i}$, its $\mathrm{CC}_{\mathrm{i}}$ with respect to $\mathrm{A}^{+}$can be found as:

$C C_{i}=\frac{S_{i-}}{S_{i-}+S_{i+}}$

Step 10: Rank the alternatives in decreasing order of $C C_{i}$ values. At this step, the alternative which has the maximum $C C_{i}$ is selected.

\section{Case Study}

The methodology is applied to a case of smart phone selection and evaluation in a Turkish company. Turkish retail market with modern retail formats and large chains has played an important role in the Turkish economy. One of the most notable components can be defined as electronics and telecommunication. There are more than 68 million phone users in Turkey. The high number of mobile phone usage rates and devices in Turkey, as well as recent publications have raised our interest to establish a decision model for choosing the most suitable smart phone. In this perspective, the evaluation methodology is used in a Turkish Company $\mathrm{X}$ (company name is not given due to privacy concerns) which aim to purchase smart phones for their white collar employees. The process is critical because of a relatively high number (approximately 60) of smart phones to be purchased. A decision committee consisting of three experts is formed with members DM1, DM2 and DM3 with the aim to determine the most appropriate smart phone among three possible alternatives. In this evaluation process, DM1 is the procurement manager who is well informed about the mobile telecom market and is knowledgeable about available smart phone alternatives. DM2 is the human resources manager of the company, who has deep information about the profile of the Company's employees and their smart phone preferences. DM3 is the quality manager who focuses on the quality of the products.

Step 1: In this step, smart phone selection criteria presented in the $2^{\text {nd }}$ section are used and decision making process is done by the aid of experts. There are three alternatives; Iphone 616 GB (A1), Samsung Galaxy S6 32GB (A2) and HTC One M9 (A3). These models are selected because of their comparable prices in the Turkish market. The criteria are summarized in Fig. 2.

Step 2: Establish DMs' weights. In this case study, the decision making procedure is carried out with the support of three DMs and the weights of DMs are determined by using Table 3 and Equation (5). The importance of linguistic variables of the three DMs is as the following: $\lambda_{1}$ presents as "medium importance" $\lambda_{2}$ presents as "very important", $\lambda_{3}$ presents as "very important". By applying Equation (5) the DMs weights are found as $0.2266,0.3867$ and 0.3867 respectively.

Step 3: The nine- and six-label linguistic evaluation scale has already been discussed in the previous section. In order to do comparisons, DMs analyze alternatives and criteria according to their interest, expertise and their intuition.

Step 4: The evaluations given by each DM for each of the three alternatives are shown in Table 5. Rating the alternatives is carried out based on Table 3. Next, according to these assessments $\mathrm{R}$ is constructed, as shown in Table 6. As an example, by using Equation 6 and $7 ; \mu_{11}=1-((1-0.5) 0.2266 *(1-0.5) 0.3867 *(1-0.5)$ $0.3867)=0.500$.

Next $\quad v_{11}=(0.5)^{0.2266} *(0.5)^{0.3867} *(0.5)^{0.3867}=$ 0.5006 and $\pi_{11}=1-0.500-0.500=0.000$. The other values are calculated similarly as stated above.

For A2 and A3, the remaining $\mathrm{R}$ values are calculated in same way. 


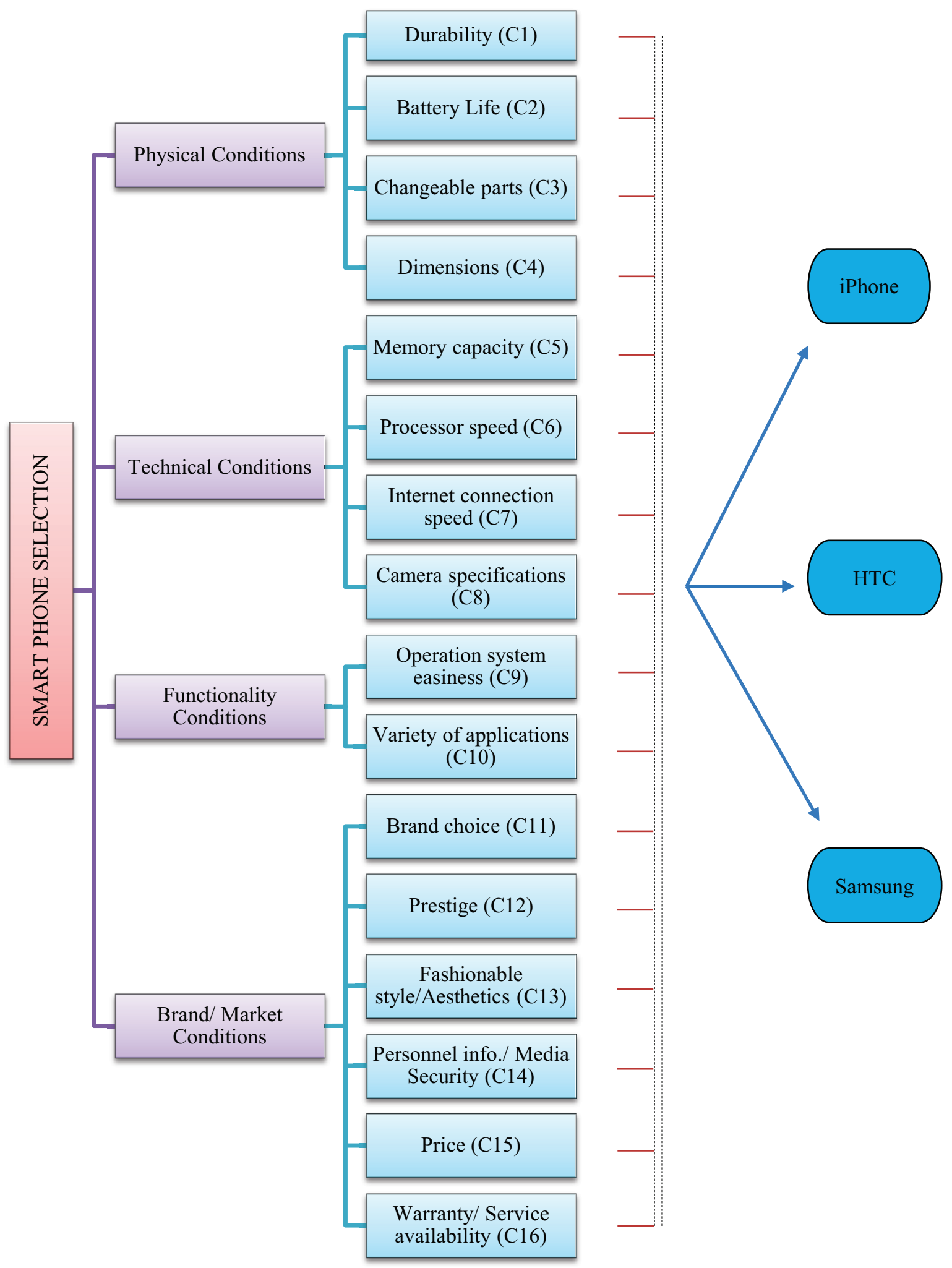

Fig. 2. The evaluation criteria for smart phone selection 
Table 5. Linguistic evaluation data of alternatives with respect to criteria

\begin{tabular}{|c|c|c|c|c|}
\hline Alternatives & Criteria & $D M 1$ & $D M 2$ & $D M 3$ \\
\hline \multirow{16}{*}{ A1 } & $\mathrm{C} 1$ & $\mathrm{M}$ & $M$ & $\mathrm{M}$ \\
\hline & $\mathrm{C} 2$ & M & M & B \\
\hline & $\mathrm{C} 3$ & $\mathrm{M}$ & M & M \\
\hline & $\mathrm{C} 4$ & VG & G & G \\
\hline & $\mathrm{C} 5$ & MD & MD & MD \\
\hline & C6 & $\mathrm{G}$ & $\mathrm{G}$ & $\mathrm{G}$ \\
\hline & $\mathrm{C} 7$ & G & G & G \\
\hline & $\mathrm{C} 8$ & MD & MD & MD \\
\hline & C9 & $\mathrm{G}$ & $\mathrm{G}$ & VG \\
\hline & $\mathrm{C} 10$ & MD & MD & M \\
\hline & $\mathrm{C} 11$ & VG & VG & VG \\
\hline & $\mathrm{C} 12$ & VG & VG & VG \\
\hline & $\mathrm{C} 13$ & VG & VG & VG \\
\hline & C14 & M & M & B \\
\hline & $\mathrm{C} 15$ & VG & VG & VG \\
\hline & C16 & VG & VG & VG \\
\hline \multirow{16}{*}{ A2 } & $\mathrm{C} 1$ & $\mathrm{G}$ & $\mathrm{G}$ & MD \\
\hline & $\mathrm{C} 2$ & G & G & G \\
\hline & $\mathrm{C} 3$ & M & M & $\mathrm{M}$ \\
\hline & $\mathrm{C} 4$ & MD & MD & MD \\
\hline & $\mathrm{C} 5$ & G & $\mathrm{G}$ & $\mathrm{G}$ \\
\hline & C6 & G & VG & G \\
\hline & C7 & G & G & G \\
\hline & $\mathrm{C} 8$ & G & M & G \\
\hline & C9 & G & G & G \\
\hline & $\mathrm{C} 10$ & M & MD & MD \\
\hline & $\mathrm{C} 11$ & VG & VG & $\mathrm{G}$ \\
\hline & $\mathrm{C} 12$ & VG & $\mathrm{G}$ & G \\
\hline & $\mathrm{C} 13$ & M & M & M \\
\hline & C14 & G & G & G \\
\hline & C15 & G & G & G \\
\hline & $\mathrm{C} 16$ & G & G & G \\
\hline \multirow{16}{*}{ A3 } & $\mathrm{C} 1$ & G & $\mathrm{G}$ & $\mathrm{G}$ \\
\hline & $\mathrm{C} 2$ & G & MD & MD \\
\hline & $\mathrm{C} 3$ & M & $\mathrm{M}$ & $\mathrm{M}$ \\
\hline & $\mathrm{C} 4$ & M & $\mathrm{M}$ & $\mathrm{M}$ \\
\hline & $\mathrm{C} 5$ & VG & VG & VG \\
\hline & C6 & $\mathrm{G}$ & VG & $\mathrm{G}$ \\
\hline & C7 & G & $\mathrm{G}$ & G \\
\hline & $\mathrm{C} 8$ & VG & VG & VG \\
\hline & C9 & G & G & G \\
\hline & $\mathrm{C} 10$ & M & MD & MD \\
\hline & C11 & MD & $\mathrm{G}$ & $\mathrm{G}$ \\
\hline & $\mathrm{C} 12$ & MD & G & MD \\
\hline & $\mathrm{C} 13$ & $\mathrm{M}$ & M & M \\
\hline & C14 & $\mathrm{G}$ & G & G \\
\hline & $\mathrm{C} 15$ & MD & M & M \\
\hline & $\mathrm{C} 16$ & VG & $\mathrm{G}$ & $\mathrm{G}$ \\
\hline
\end{tabular}

Step 5: Construct and evaluate weights of criteria according to DMs' viewpoints. Table 2 is utilized for corresponding linguistic terms for evaluation. Using DMs' assessments, Table 7 is constructed and then these assessments are aggregated with the same approach. By using Equation 7, the weights of criteria are calculated and can be seen in Table 8 .
Table 6. Aggregated intuitionistic fuzzy decision matrix (R)

\begin{tabular}{cllll}
\hline Alternatives & Criteria & $\mathbf{D M 1}$ & $\mathbf{D M 2}$ & $\mathbf{D M 3}$ \\
\hline \multirow{4}{*}{ C1 } & $\underline{0.500}$ & $\underline{0.500}$ & $\underline{0.000}$ \\
C2 & 0.415 & 0.537 & 0.048 \\
C3 & 0.500 & 0.500 & 0.000 \\
C4 & 0.640 & 0.203 & 0.156 \\
C5 & 0.500 & 0.400 & 0.100 \\
C6 & 0.600 & 0.250 & 0.150 \\
A1 & C7 & 0.600 & 0.250 & 0.150 \\
& C8 & 0.500 & 0.400 & 0.100 \\
C9 & 0.666 & 0.175 & 0.158 \\
& C10 & 0.500 & 0.436 & 0.064 \\
C11 & 0.750 & 0.100 & 0.150 \\
C12 & 0.750 & 0.100 & 0.150 \\
C13 & 0.750 & 0.100 & 0.150 \\
C14 & 0.415 & 0.537 & 0.048 \\
C15 & 0.750 & 0.100 & 0.150 \\
C16 & 0.750 & 0.100 & 0.150 \\
\hline
\end{tabular}

Table 7. Linguistic evaluation data of criteria

\begin{tabular}{cccc}
\hline Criteria & DM1 & DM2 & DM3 \\
\hline C1 & MI & MI & MI \\
C2 & M & MI & I \\
C3 & M & MI & MI \\
C4 & VI & I & I \\
C5 & M & MI & I \\
C6 & M & M & I \\
C7 & M & M & I \\
C8 & M & MI & I \\
C9 & U & M & MI \\
C10 & U & M & MI \\
C11 & I & VI & I \\
C12 & I & I & I \\
C13 & I & MI & MI \\
C14 & MI & I & I \\
C15 & MI & VI & I \\
C16 & MI & I & I \\
\hline
\end{tabular}

Table 8. Calculated weight (W) of each criteria

\begin{tabular}{ccc}
\hline $\boldsymbol{\mu}$ & $\mathbf{v}$ & $\prod$ \\
\hline 0.700 & 0.200 & 0.100 \\
0.712 & 0.188 & 0.100 \\
0.663 & 0.246 & 0.091 \\
0.829 & 0.000 & 0.171 \\
0.712 & 0.188 & 0.100 \\
0.649 & 0.268 & 0.082 \\
0.649 & 0.268 & 0.082 \\
0.712 & 0.188 & 0.100 \\
0.557 & 0.351 & 0.092 \\
0.557 & 0.351 & 0.092 \\
0.847 & 0.000 & 0.153 \\
0.800 & 0.100 & 0.100 \\
0.726 & 0.171 & 0.103 \\
0.781 & 0.117 & 0.102 \\
0.832 & 0.000 & 0.168 \\
0.781 & 0.117 & 0.102 \\
\hline
\end{tabular}


Step 6: The aggregated weighted intuitionistic fuzzy decision matrix is formed with the Equation 8, and the result is provided in Table 9.

Table 9. Intuitionistic fuzzy decision matrix of A1

\begin{tabular}{clccc}
\hline Alternatives & Criteria & $\boldsymbol{\mu}$ & $\mathbf{v}$ & $\prod$ \\
\hline \multirow{6}{*}{ C1 } & 0.350 & $\underline{0.600}$ & 0.050 \\
& C2 & 0.296 & 0.624 & 0.081 \\
& C3 & 0.332 & 0.623 & 0.045 \\
& C4 & 0.531 & 0.203 & 0.266 \\
& C5 & 0.356 & 0.513 & 0.131 \\
& C6 & 0.390 & 0.451 & 0.159 \\
A1 & C7 & 0.390 & 0.451 & 0.159 \\
& C8 & 0.356 & 0.513 & 0.131 \\
& C9 & 0.371 & 0.465 & 0.164 \\
& C10 & 0.279 & 0.634 & 0.088 \\
& C11 & 0.635 & 0.100 & 0.265 \\
& C12 & 0.600 & 0.190 & 0.210 \\
& C13 & 0.545 & 0.254 & 0.201 \\
& C14 & 0.324 & 0.591 & 0.085 \\
& C15 & 0.624 & 0.100 & 0.276 \\
& C16 & 0.586 & 0.205 & 0.209 \\
\hline
\end{tabular}

For $\mathrm{A} 2$ and $\mathrm{A} 3$, the remaining $\mu, \mathrm{v}$ and $\prod$ values are calculated in same way.

Step 7: Obtain the intuitionistic fuzzy positive and negative ideal solutions with the Equations 10-14. The results are given in Table 10 . For $\mathrm{A} 2$ and $\mathrm{A} 3$, the remaining $r$ values are calculated in same way.

Table 10. Intuitionistic fuzzy positive and negative ideal solutions of A1

\begin{tabular}{llll}
\hline r1 & $\underline{0.420}$ & 0.400 & 0.180 \\
r2 & 0.427 & 0.391 & 0.182 \\
r3 & 0.332 & 0.623 & 0.045 \\
r4 & 0.531 & 0.203 & 0.266 \\
r5 & 0.534 & 0.269 & 0.197 \\
r6 & 0.433 & 0.397 & 0.171 \\
r7 & 0.390 & 0.451 & 0.159 \\
r8 & 0.534 & 0.269 & 0.197 \\
r9 & 0.371 & 0.465 & 0.164 \\
r10 & 0.279 & 0.624 & 0.097 \\
r11 & 0.635 & 0.100 & 0.265 \\
r12 & 0.600 & 0.190 & 0.210 \\
r13 & 0.545 & 0.254 & 0.201 \\
r14 & 0.468 & 0.338 & 0.194 \\
r15 & 0.624 & 0.100 & 0.276 \\
r16 & 0.586 & 0.205 & 0.209 \\
\hline
\end{tabular}

Step 8: The separation measures of intuitionistic fuzzy sets are calculated by using Equation 15 and 16. As an example, the positive separation measure of A1 is calculated as follows:

$$
\begin{aligned}
& \mathrm{S}^{+}=\frac{1}{2}(|0.350-0.420|+|0.600-0.400|+ \\
& |0.500-0.180| \ldots+|0.209-0.209|)=1.237
\end{aligned}
$$

The remaining $\mathrm{S}^{-}$values are calculated in same way.

Step 9: Calculate the $\mathrm{CC}_{\mathrm{i}}$ to the intuitionistic ideal solution. Table 11 shows the final ranking and $\mathrm{CC}_{\mathrm{i}}$.

Table 11. Separation measures and $\mathrm{CC}_{\mathrm{i}}$ of each alternative

\begin{tabular}{cccc}
\hline Alternatives & $S^{+}$ & $S^{-}$ & $\mathrm{CC}_{\mathrm{i}}$ \\
\hline $\mathrm{A} 1$ & 1.237 & 1.573 & $\mathbf{0 . 5 6 0}$ \\
$\mathrm{A} 2$ & 1.340 & 1.470 & 0.523 \\
$\mathrm{~A} 3$ & 1.621 & 1.190 & 0.423 \\
\hline
\end{tabular}

Step 10: According to the $\mathrm{CC}_{\mathrm{i}}$ values, the product $\mathrm{A}$ 1 (Iphone $616 \mathrm{~GB}$ ) is identified as the best ranking phone with a score of 0.560 .

\section{Comparison / Sensitivity Analysis}

\subsection{Comparison with Chen's fuzzy TOPSIS}

A comparative analysis is carried out to investigate the consistency of the rank and weight of the alternatives selection. The work that makes use of IF-TOPSIS is tested and compared with the results of Chen's ${ }^{60}$ fuzzy TOPSIS method. Table 12 presents the ranking of the alternatives according to their performance indices. According to the overall result of Fuzzy TOPSIS, A2 is the best alternative followed by A1 and A3 $(\mathrm{A} 2>\mathrm{A} 1>\mathrm{A} 3)$. The ranking of the alternatives changes very small comparing to the results of utilized IFTOPSIS method (A1 $>$ A2 $>$ A 3$)$.

Table 12. Performance indices of each alternative by using fuzzy TOPSIS

\begin{tabular}{cc}
\hline Alternatives & Performance index \\
\hline A1 & 0.0506 \\
A2 & 0.0522 \\
A3 & 0.0499 \\
\hline
\end{tabular}

From this research, the ranking orders are slightly inconsistent with Fuzzy TOPSIS due to use of different preference scales of the DMs. However, the utilized preference scale with hesitation degree is based on the IFS notation. As a summary, it can be seen that the differences in the values may come from the intuitionistic evaluations of the utilized method, providing more flexible and informative definitions of fuzzy sets. 


\subsection{Sensitivity analysis}

A sensitivity analysis is performed in order to determine whether the final solution is robust to changes of the weights of a specific expert. Considering that the priorities are remarkably dependent on subjective judgments of the DMs, the stability of the final ranking under different weights should be checked out. With regard to this purpose, it is better to execute a sensitivity analysis based on a set of cases that reflect different views on the relative importance of the determinants. By altering the weights and providing some insights into the results are the main idea of the analysis. Initially, DM1 has "medium", DM2 and DM3 have "very important" linguistic importance weights. This is the current situation and named as CASE 1. In the sensitivity analysis (see Table 13) the importance weights are changed to "very important" for DM1, "medium" for DM2 and "important" for DM3 - named as CASE 2. In another case, named as CASE3, weights are changed to "important" for DM1, "very important" for DM2 and "medium" for DM3. The results of cases are presented in Tables 14 and 15.

Table 13. Different importance weights of experts

\begin{tabular}{cccc}
\hline Experts (DM) & $\begin{array}{c}\text { Importance } \\
\text { weights } \\
\text { CASE } \\
1\end{array}$ & $\begin{array}{c}\text { Importance } \\
\text { weights } \\
\text { CASE } \\
2\end{array}$ & $\begin{array}{c}\text { Importance } \\
\text { weights } \\
\text { CASE } \\
3\end{array}$ \\
\hline $\begin{array}{c}\text { DM1 (Marketing and } \\
\text { sales manager) }\end{array}$ & 0.227 & 0.406 & 0.344 \\
DM2 (Human resources \\
manager) & 0.387 & 0.238 & 0.414 \\
DM3 (Quality manager) & 0.387 & 0.356 & 0.242 \\
\hline
\end{tabular}

Table 14. Separation measures and $\mathrm{CC}_{\mathrm{i}}$ of each alternative (CASE 2)

\begin{tabular}{cccc}
\hline Alternatives & $S^{+}$ & $S^{-}$ & $\mathrm{CC}_{\mathrm{i}}$ \\
\hline $\mathrm{A} 1$ & 1.203 & 1.631 & 0.575 \\
$\mathrm{~A} 2$ & 1.310 & 1.525 & 0.538 \\
$\mathrm{~A} 3$ & 1.628 & 1.207 & 0.426 \\
\hline
\end{tabular}

Table 15. Separation measures and $\mathrm{CC}_{\mathrm{i}}$ of each alternative (CASE 3)

\begin{tabular}{cccc}
\hline Alternatives & $S^{+}$ & $S^{-}$ & $\mathrm{CC}_{\mathrm{i}}$ \\
\hline $\mathrm{A} 1$ & 1.207 & 1.584 & 0.568 \\
$\mathrm{~A} 2$ & 1.305 & 1.486 & 0.532 \\
$\mathrm{~A} 3$ & 1.597 & 1.193 & 0.428 \\
\hline
\end{tabular}

It is seen that as no significant changes occur in the most important alternative, the results are not sensitive to the importance weights of DMs. In other words, the sensitivity analysis shows that the changes in the DMs' weights do not cause any change in the ranking of the considered smart phone alternatives. This means that our decision is robust against possible changes in DMs' weights.

\section{Conclusion}

The main objective of this paper is to identify the most suitable smart phone alternative by taking various decision criteria and consumer preferences into account. Evaluation of smart phone options includes subjective and qualitative judgments and requires different complex factors. For this reason, the evaluation problem needs MCDM methods to correctly select the most appropriate smart phone alternative. In GDM problems, DMs' opinions may differ substantially. Therefore, to come to a meaningful and reliable solution, it is preferable to consider group decision in decision process. In this study, IF-TOPSIS is used with a GDM approach which allowed us to mathematically represent the uncertainty and vagueness and reflect the DMs' perception in the decision process. Besides, the model is illustrated with a case study to exemplify the decision framework.

This study presents a novel technique that uses an MCDM based GDM approach with IF-TOPSIS. To authors' best knowledge, this study has originality as it is the first application of IF-TOPSIS in literature with a case study of the smart phone selection problem. However, literature needs more studies conducted in other industrial fields using IF-TOPSIS.

In this paper, preferences of clients (i.e. employees of Company X) are gathered and integrated into the model with the opinions of the three managers of the same company. The aim of the next paper is to come up with another structure where every employee provides his or her personal assessment into a computersupported, automated system that is able to collect a large number of assessments from employees and to easily integrate them into the decision procedure.

Future studies are encouraged to consider more alternatives by taking the inherent complexity of the problem into account. This decision framework is planned to be extended to other disciplines as next steps. Other extended studies can include "the hesitant fuzzy linguistic terms" with TOPSIS method ${ }^{61-64}$ as well. 


\section{Acknowledgements}

The authors kindly thank for the contributions of the experts committee members. Gülçin Büyüközkan acknowledges the financial support of the Galatasaray University Research Fund (Project Number: 16.402.002).

\section{References}

1. Turk-Telekom 2015 Data, available at: http://www.ttinvestorrelations.com. (accessed: 20.06.2015).

2. Information and Communication Technologies Authority (ICTA), electronic communications market in Turkey market data (2015 q1): available at:http://eng.btk.gov.tr. (accessed: 20.06.2015).

3. P. Mahatanankoon, H. J. Wen, and B. Lim, Consumerbased m-commerce: exploring consumer perception of mobile applications, Computer Standards \& Interfaces 27(4) (2005) 347-357.

4. M.-H. Hsiao, and L.-C. Chen, Smart phone demand: An empirical study on the relationships between phone handset, Internet access and mobile services, Telematics and Informatics 32(1) (2015) 158-168.

5. G. Işıklar, and G. Büyüközkan, Using a multi-criteria decision making approach to evaluate mobile phone alternatives, Computer Standards \& Interfaces 29(2) (2007) 265-274.

6. G. Çifçi, and G. Büyüközkan, A Fuzzy MCDM Approach to Evaluate Green Suppliers, International Journal of Computational Intelligence Systems 4(5) (2011) 894-909.

7. A. Özgen, G. Tuzkaya, U. R. Tuzkaya, and D. Özgen, A Multi-Criteria Decision Making Approach for Machine Tool Selection Problem in a Fuzzy Environment, International Journal of Computational Intelligence Systems 4(4) (2012) 431-445.

8. G. Wei, X. Zhao, and R. Lin, Some Induced Aggregating Operators with Fuzzy Number Intuitionistic Fuzzy Information and their Applications to Group Decision Making, International Journal of Computational Intelligence Systems 3(1) (2010) 84-95.

9. G. Büyüközkan, O. Feyzioglu, and G. Çifçi, Fuzzy MultiCriteria Evaluation of Knowledge Management Tools, International Journal of Computational Intelligence Systems 4(2) (2012) 184-195.

10. I. Palomares, R M. Rodríguez, and L. Martínez López, An attitude-driven web consensus support system for heterogeneous group decision making, Expert Systems with Applications 40(1) (2013)139-149.

11. I. Palomares, F J. Estrella, L. Martínez, and F. Herrera, Consensus under a Fuzzy Context: Taxonomy, Analysis Framework AFRYCA and Experimental Case of Study, Information Fusion 20 (2014) 252-271.

12. F. E. Boran, An applicaton of intuitionistic fuzzy set on personnel selection, Thesis for the degree of M.S.c. in industrial engineering, Gazi University Institute of Science and Technology, 2009.

13. C.L. Hwang, and K.P. Yoon, Multiple attribute decisionmaking: Methods and application, Springer, New York, 1981.

14. F. E. Boran, S. Genç, M. Kurt, and D. Akay, A multicriteria intuitionistic fuzzy group decision making for supplier selection with TOPSIS method, Expert Systems with Applications 36 (8) (2009)11363-11368.

15. S. Perçin, and C. Kahraman, An Integrated Fuzzy MultiCriteria Decision-Making Approach for Six Sigma Project Selection, International Journal of Computational Intelligence Systems 10 (2010) 610-621.

16. K. T. Atanassov, Intuitionistic fuzzy sets. Fuzzy Sets and Systems 20 (1986) 87-96.

17. L. Abdullah, and L. Najib, A new preference scale of intuitionistic fuzzy analytic hierarchy process in multicriteria decision making problems, Journal of Intelligent \& Fuzzy Systems 26(2) (2014) 1039-1049.

18. L. Abdullah, and L. Najib, Sustainable energy planning decision using the intuitionistic fuzzy analytic hierarchy process: choosing energy technology in Malaysia, International Journal of Sustainable Energy, DOI: 10.1080/14786451.2014. 907292, 2014.

19. Z. Xu, and H. Liao, Intuitionistic Fuzzy Analytic Hierarchy Process, IEEE Transactions on Fuzzy Systems 22(4) (2014) 749-761.

20. Z. Yue, TOPSIS-based group decision-making methodology in intuitionistic fuzzy setting, Information Sciences 277(1) (2014) 141-153.

21. K. Govindan, R. Khodaverdi, and A. Vafadarnikjoo, Intuitionistic fuzzy based DEMATEL method for developing green practices and performances in a green supply chain, Expert Systems with Applications 42(20) (2015) 7207-7220.

22. A. Maldonado-Macías, A. Alvarado, J.L. García, and C.O. Balderrama, Intuitionistic fuzzy TOPSIS for ergonomic compatibility evaluation of advanced manufacturing technology, International Journal of Advanced Manufacturing Technology 70(9) (2014) 22832292.

23. D. Joshi, and S. Kumar, Intuitionistic fuzzy entropy and distance measure based TOPSIS method for multi-criteria decision making, Egyptian Informatics Journal 15 (2) (2014) 97-104.

24. M. Haverila, Mobile phone feature preferences, customer satisfaction and repurchase intent among male users, Australasian Marketing Journal 19(4) (2011) 238-246.

25. E. Bayraktar, E. Tatoglu, A. Turkyilmaz, D. Delen, and S. Zaim, Measuring the efficiency of customer satisfaction and loyalty for mobile phone brands with DEA, Expert Systems with Applications 39(1) (2012) 99106.

26. A.A. Economides, and A. Grousopoulou, Students' thoughts about the importance and costs of their mobile devices' features and services, Telematics and Informatics 26(1) (2009) 57-84.

27. S.-K. Hu, M.-T. Lu, and G.-H. Tzeng, Exploring smart phone improvements based on a hybrid MCDM model, 
Expert Systems with Applications 41(9) (2014) 44014413.

28. T. Rahul, and R. Majhi, An adaptive nonlinear approach for estimation of consumer satisfaction and loyalty in mobile phone sector of India, Journal of Retailing and Consumer Services 21(4) (2014) 570-580.

29. M. Haverila, What do we want specifically from the cell phone? An age related study, Telematics and Informatics 29(1) (2012) 110-122.

30. M. Haverila, Cell phone usage and broad feature preferences: A study among Finnish undergraduate students, Telematics and Informatics 30(2) (2013) 177188.

31. S. Mokhlis, and A. Y. Yaakop, Consumer Choice Criteria in Mobile Phone Selection: An Investigation of Malaysian University Students, International Review of Social Sciences and Humanities, 2(2) (2012) 203-212.

32. C.H. Chen, L.P. Khoo, and W. Yan, Evaluation of multicultural factors from elicited customer requirements for new product development, Research in Engineering Design 14(3) (2003) 119-130.

33. D.-N. Chen, P. J.-H. Hu, Y.-R. Kuo, and T.-P. Liang, A Web-based personalized recommendation system for mobile phone selection: Design, implementation, and evaluation, Expert Systems with Applications 37(12) (2010) 8201-8210.

34. C. Ling, W. Hwang, and G. Salvendy, Diversified users' satisfaction with advanced mobile phone features, Universal Access in the Information Society 5(2) (2006) 239-249.

35. J.M. Noguera, M J. Barranco, R.J. Segura, and L. Martínez López, A Mobile 3D-GIS Hybrid Recommender System for Tourism, Information Sciences 215 (2012) 37-52.

36. Y. Yun, and S.-H. Cha, Guitar application programming for smart phone, Communications in Computer and Information Science 300-305. Springer Berlin, Heidelberg, 2012.

37. K. T. Atanassov, Intuitionistic fuzzy sets, (Heidelberg: Springer, 1999).

38. L.A Zadeh, Fuzzy sets. Journal of Information and Control 8 (1965) 338-353.

39. M. Xia, and Z. Xu, Entropy/cross entropy-based group decision making under intuitionistic fuzzy environment. Information Fusion 13(1) (2012) 31-47.

40. Z. S. Xu, Intuitionistic preference relations and their application in group decision making, Information Sciences 177(11) (2007) 2363-2379.

41. L. Martinez, D. Ruan, and F. Herrera, Computing with Words in Decision support Systems: An overview on Models and Applications, International Journal of Computational Intelligence Systems 3(4) Special Issue (2010) 382-395.

42. L. Martinez, M. Espinilla, and L. G. Perez, A Linguistic Multigranular Sensory Evaluation Model for Olive Oil, International Journal of Computational Intelligence Systems 1(2) (2008) 148-158.

43. F. E. Boran, K. Boran, and T. Menlik, The evaluation of renewable energy technologies for electricity generation in Turkey using intuitionistic fuzzy TOPSIS, Energy sources 7(1) (2012) 81-90.

44. R. de Andres, M. Espinilla, and L. Martinez, An Extended Hierarchical Linguistic Model for Managing Integral Evaluation, International Journal of Computational Intelligence Systems 3(4) Special Issue (2008) 486-500.

45. R M. Rodríguez, and L. Martínez, A Consensus Model for Group Decision Making with Hesitant Fuzzy Linguistic Information, International Conference on Intelligent Systems and Knowledge Engineering 2015, DOI 10.1109/ISKE.2015.31.

46. F. J. Quesadaa, I. Palomares, and L. Martínez, Managing experts behavior in large-scale consensus reaching processes with uninorm aggregation operators, Applied Soft Computing 35 (2015) 873-887.

47. J. Liu, R M. Rodríguez, and L. Martínez, Preface New trends of information fusion in decision making, Information Fusion 29 (2016) 87-88.

48. Z. S. Xu, and R.R. Yager Some geometric aggregation operators based on intuitionistic fuzzy sets, International Journal of General Systems 35(4) (2006) 417- 433.

49. Y. He, H. Chen, L. Zhou, J. Liu, and Z. Tao, Intuitionistic fuzzy geometric interaction averaging operators and their application to multi-criteria decision making, Information Sciences 259 (2014)142-159.

50. S. J. Chen, and C. L. Hwang, Fuzzy multiple attribute decision-making methods and application, In Lecture notes in economics and mathematical systems, (New York: Springer, 1992).

51. F. Ye, An extended TOPSIS method with interval-valued intuitionistic fuzzy numbers for virtual enterprise partner selection, Expert Systems with Applications 37(10) (2010) 7050-7055.

52. F. E. Boran, An integrated intuitionistic fuzzy multi criteria decision making method for facility location selection, Mathematical and Computational Applications 16(2) (2011) 487-496.

53. C. Tan, A multi-criteria interval-valued intuitionistic fuzzy group decision making with Choquet integralbased TOPSIS, Expert Systems with Applications 38(4) (2011) 3023-3033.

54. Z.-X. Su, M.-Y. Chen, G.-P. Xia, and L. Wang, An interactive method for dynamic intuitionistic fuzzy multiattribute group decision making, Expert Systems with Applications 38(12) (2011) 15286-15295.

55. G. Intepe, E. Bozdag, and T. Koc, The selection of technology forecasting method using a multi-criteria interval-valued intuitionistic fuzzy group decision making approach, Computers \& Industrial Engineering 65(2) (2013) 277-285.

56. B.Vahdani, S. Meysam Mousavi, R. TavakkoliMoghaddam, and H. Hashemi, A new design of the elimination and choice translating reality method for multi-criteria group decision-making in an intuitionistic fuzzy environment, Applied Mathematical Modelling 37(4) (2013) 1781-1799.

57. M. Kucukvar, S. Gumus, G. Egilmez, and O. Tatari, Ranking the sustainability performance of pavements: An 
intuitionistic fuzzy decision making method, Automation in Construction 40(15) (2014) 33-43.

58. T.Y. Chen, The inclusion-based TOPSIS method with interval-valued intuitionistic fuzzy sets for multiple criteria group decision making, Applied Soft Computing 26 (2015) 57-73.

59. X. Zhang, and Z. Xu, Soft computing based on maximizing consensus and fuzzy TOPSIS approach to interval-valued intuitionistic fuzzy group decision making, Applied Soft Computing 26 (2015) 42-56.

60. C.T. Chen, Extensions of the TOPSIS for group decision making under fuzzy environment, Fuzzy Sets and Systems, 114(1) (2000) 1-9.

61. R M. Rodríguez, L. Martínez, and F. Herrera, Hesitant Fuzzy Linguistic Term Sets for Decision Making, IEEE Transactions on Fuzzy Systems 20(1) (2012) 109-119.
62. H. Liu, and R M. Rodríguez, A fuzzy envelope for hesitant fuzzy linguistic term set and its application to multi criteria decision making, Information Sciences 258(10) (2014) 220-238.

63. F. J. Estrella, R. M. Rodríguez, and L. Martínez, A Hesitant Linguistic Fuzzy TOPSIS Approach Integrated into FLINTSTONES, Proceedings of the 2015 Conference of the International Fuzzy Systems Association and The European Society for Fuzzy Logic and Technology.

64. R.M. Rodríguez, B. Bedregal, H. Bustince, Y.C. Dong, B. Farhadinia, C. Kahraman, L. Martínez, V. Torra, Y.J. $\mathrm{Xu}$, Z.S. Xu, and F. Herrera, A position and perspective analysis of hesitant fuzzy sets on information fusion in decision making, Information Fusion 29 (2016) 89-97. 